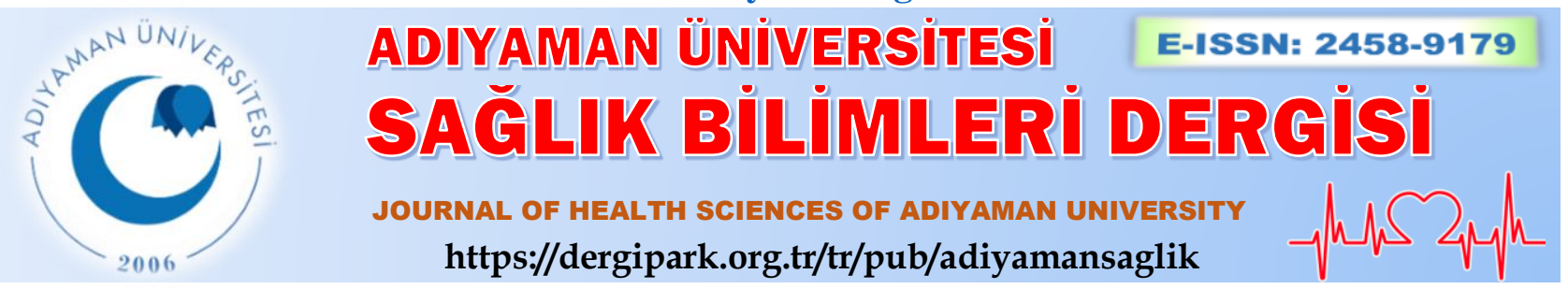

Derleme/Review

\title{
Popüler kültür ve hemşirelik
}

\section{Popular culture and nursing}

\author{
Ebru ÖZTÜRK ÇOPUR ${ }^{1 @(D)}$ Zehra CAN $^{1}(\mathbb{D})$ Fatma KARASU$^{1}$ (D) , Hasan Hüseyin ÇAM ${ }^{1}$ (D) \\ ${ }^{1}$ Kilis 7 Aralık Üniversitesi, Yusuf Şerefoğlu Sağlık Bilimleri Fakültesi, 79090, Kilis-Türkiye
}

Atıf gösterme/Cite this article as: Öztürk Çopur E, Can Z, Karasu F, Çam HH. Popüler kültür ve hemşirelik. $A D Y \ddot{U}$ Sağllk Bilimleri Derg. 2020;6(3):380-385. doi:10.30569.adiyamansaglik.746445

\section{$\ddot{O} z$}

Popüler kültür toplum tarafından kabul gören inançlar, uygulamalar ve tüm bunların örgütlendiği nesneler olarak tanımlanmaktadır. Günümüzde popüler kültür toplum üzerinde önemli bir etkiye sahiptir. Kitle iletişim araçlarıyla güçlenen ve etkisi artan popüler kültür toplumun gerçeklikten ve düşünmekten uzaklaşmasına neden olur. Popüler kültürün etkisini günlük yaşamdan, eğitime, bilime, üretime kadar hemen her alanda görebiliriz. Hemşirelik eğitimi ve mesleği de popüler kültürden etkilenmiştir. Hemşirelik geçmişten bu yana kültürel, teknolojik ve sosyal gelişmeler çerçevesinde kendini geliştiren, toplumun her kesimine ulaşan ve yarar sağlayan, kuramları olan, uygulama ve araştırma bilimlerini kapsayan bir meslek olarak karşımıza çıkmaktadır. Günümüzde her alanda varlığını gösteren hemşireler toplumun sağlık sisteminde vazgeçilmez unsurlardır. En eski meslek gruplarından biri olan hemşirelik popüler kültürün etkisiyle geçmişten bu yana toplumsal olarak kalıplaşmış imgelere maruz kalmıştır. Popüler kültürün ortaya çıkması ve kitle iletişim araçlarıyla evrensel bir yayılım göstermesi hemşirelik mesleği ve hemşirelik imajını da etkilemiştir. Bu etki genelde olumsuz öğeler içermiş ve bu durumdan dolayı hemşireler benlik saygısını yitirme, toplum tarafından küçümsenme ve baskı gibi sorunlar yaşamışlardır. Derlememizde popüler kültür bağlamında hemşirelik mesleğinin incelenmesi amaçlamaktadır.

Anahtar Kelimeler: Kültür; Popüler kültür; Hemşirelik.

\begin{abstract}
Popular culture is defined as community accepted beliefs, practices, and objects that all these are organized. Nowadays popular culture has an important effects on the community. Popular culture, which becomes stronger and gets more effective with mass media causes the society to move away from reality and thinking. We can see the effect of popular culture in almost every area from daily life to education, science and production. Nursing education and profession have not avoided the effect of popular culture. Since the past, nursing confront us as a profession that cover research sciences and application, provide benefit and reach every segment of society, develop itself with in the frame work of cultural, technological and social developments. Nowadays nurses showing their presence in all area as are indispensable elements in health care. Since the past, being nursing one of the oldest jobs groups has been exposured socially stereo typed images with the effect of popular culture. Emerging of popular culture and with mass medias showing a global spread has been affected nursing profession and nursing image. This effect has included negative components in general and due to this situation nurses have been lived problems such as pressure, under estimation by community, losing self-esteem. Our review aims to examine nursing profession in the context of popular culture.
\end{abstract}

Keywords: Culture; Popular culture; Nursing.

Yazışma Adresi/Address for Correspondence: Ebru ÖZTÜRK ÇOPUR, Kilis 7 Aralık Üniversitesi, Yusuf Şerefoğlu Sağlık Bilimleri Fakültesi, 79090, Kilis-Türkiye, E-mail: ebruozturkcopur@kilis.edu.tr

Geliş Tarihi/Received:01.06.2020Ｔabul Tarihi/Accepted:25.06.2020 $\quad$ Yayım Tarihi/Published online:03.12.2020 


\section{Giriş}

Günümüzde neredeyse tüm dünyada etkisini gösteren popüler kültür genel olarak toplum tarafindan kabul gören inançlar, uygulamalar ve tüm bunların örgütlendiği nesneler olarak tanımlanmaktadır. Kitle iletişim araçlarıyla güçlenen ve etkisi artan bir kültür olan popüler kültür toplumu düşünmeden uzaklaştırarak gerçeklik algısını yitirmesine neden olur. ${ }^{1}$ Popüler kültür Türkiye'de batılılaşmaya yönelik olmuştur. Ancak ilerleyen zamanlarda popüler kültürde Türk kültürüne ait izlere de rastlanmıştır. Popüler kültür Türkiye'de batılılaşmanın etkisiyle müzik, TV programları ve dizilerinde, çizgi romanlarda ve son y1llarda gelişen internet sayesinde video klip ve sosyal medyada karşımıza çıkmaktadır. ${ }^{2}$ Popüler kültürün toplum üzerinde önemli etkiye sahip olması toplumsal değişimlere neden olmaktadır. Popüler kültür toplumu tüketime yönlendirme, kültürel değerlerin kaybolması, bireyleri farklı düşüncelerden uzaklaştırarak tek bir düşünce üzerinde toplamak gibi toplum üzerinde olumsuz etkilere sahiptir. ${ }^{3}$

Hemşirelik mesleği toplumun sağlığını korumak, bakım vermek, sağlığın sürdürülebilmesini sağlamak, tedavi etmek gibi önemli yükümlülüklere sahip bir meslek grubudur. Hemşirelik geçmişten bu yana kültürel, teknolojik ve sosyal gelişmeler çerçevesinde kendini geliştiren, toplumun her kesimine ulaşan ve yarar sağlayan, kuramları olan, uygulama ve araştırma bilimlerini kapsayan bir meslektir. Günümüzde her alanda varlığını gösteren hemşireler toplumun sağlık sisteminde vazgeçilmez unsurlardır. Sağlığın neredeyse her alanında bulunan ve sağlığın geliştirilmesinde büyük etkisi olan hemşireler hala toplumda gerekli değeri görememektedir. ${ }^{4-5}$ En eski meslek gruplarından biri olan hemşireler popüler kültürün etkisiyle toplumsal olarak belli bir alg1 ve kalıplara maruz kalmıştır, geçmişten günümüze gelen hemşirelik imajları melek tasviri, doktorların yardımcıları, yaramaz hemşireler, kötü hemşireler olarak karşımıza çıkmaktadır. Popüler kültürün ortaya çıkması ve kitle iletişim araçlarıyla evrensel bir yayılım göstermesi ile bu olumsuz öğeler hemşirelik mesleğinin ve hemşirelik imajının kötü algılanmasına dolayısıyla hemşirelerin benlik saygını yitirmesine, toplum tarafindan küçümsenme ve baskı gibi sorunlar yaşamasına neden olmuştur. ${ }^{6}$

\section{Popüler kültür ve hemşirelik kavramlarının tanımı}

\section{Popüler kültür}

Popüler kültür, içeriğinde çok çeşitlilik bulundurması nedeniyle tek bir tanım yapılamayan ancak genel olarak nüfusun büyük çoğunluğunun paylaştığı bir kültürdür. ${ }^{7}$ Türk Dil Kurumu'na göre; "Belli bir dönem içinde geçerli olan, hızlı üretilen ve hızlı tüketilen kültürel öğelerin bütünü" olarak tanımlanmaktadır. ${ }^{8} 20$. yüzyıldan itibaren hızla gelişmekte olan teknolojik gelişmeler ve dolayısıyla hızla yayılım gösteren kitle iletişim araçları sayesinde popüler kültürün etkisi daha da artmıştır. Günümüzde internet, gazete, dergi ve özellikle televizyon gibi kitle iletişim araçlarının etkisiyle medya kavramı oluşmuştur. Popüler kültür kavramı medyanın etkisiyle toplumdaki geleneksel kültür üzerinde değişimlere neden olan ve toplumu tüketime yönlendiren bir kültür olarak karşımıza çıkmaktadır. ${ }^{9-10}$

Popüler kültürün özelliklerini inceleyecek olursak;

- Biçim olarak ele alındığında orta düzeyde karmaşık yapıya sahiptir.

- Elde etmesi kolay ve ucuzdur.

- Teknolojik gelişmelerden ve ortamdan etkilenir.

- Geleneksel kültürü yenilenmiş şekilde sunar.

- Üretici ve tüketici farklı statülere sahiptir. Her zaman tüketen tarafa yönelir.

- Sürekli yenilenen ve geliştirilen bir yapıya sahiptir. ${ }^{11}$

Popüler kültürün olumsuz etkileri ise 4 başlık altında incelenebilmektedir.

Toplum üzerindeki olumsuz etkileri: Geleneksel kültür üzerinde değişimler oluşturduğundan, toplumun kültürel özelliklerini kaybetmesine ve daha pasif bir toplum olmasına yol açabilir.

Kültür üzerindeki olumsuz etkileri: Kültürün önemsizleşmesine neden olarak hızlı 
tüketim etmenleriyle toplumda kültürün kendisini göstermesinin önüne geçer.

Tüketici üzerindeki olumsuz etkileri: Tüketici üzerinde gerçek olmayan duygular oluşturarak duygusal yıpranmaya neden olabilir.

Popüler kültür oluşumundaki olumsuz etkileri: Kazanç sağlamak için yapıldığından sadece tüketen grup üzerinden oluşturulur. ${ }^{10}$

\section{Hemşirelik kavramı}

Hemşirelik kavramı, birey ve toplumda sağllğ 1 koruma, geliştirme, iyileştirme ve sürdürmede önemli bir meslek olarak karşımıza çıkmaktadır. ${ }^{12}$ Uluslararası Hemşireler Konseyi (The International Council of Nurses- ICN) hemşireliği her bireye bakım verme, hastalıkları önleme ve sağlığın sürdürülmesinin desteklenmesinde sorumlulukları olan meslek olarak tanımlar. ${ }^{13}$ Amerikan Hemşireler Derneği (American Nurses Association-ANA) hemşirelik mesleğini toplumun gereksinimlerini gidermek için sürekli gelişen ve yenilenen bir meslek olarak tanımlar. ${ }^{14}$ Ülkemizde ise Türk Hemşireler Derneği hemşirelik mesleğini, bireyin ve toplumun sağlığını koruma, geliştirme, iyileştirmede, sağlığın sürdürülmesinin sağlanmasında gerekli bakım, eğitim, araştırma, geliştirme ve danışmanlık yapan bir meslek olarak tanımlamaktadır. ${ }^{15}$ Hemşirelik mesleğinin tarihsel gelişimi incelendiğinde; hemşirelik mesleği geçmişte hekimlere tabi tutulurken, son zamanlardaki gelişmeler ve değişimlerle özerk bir meslek haline gelmeye başlamıştır. Ayrıca geçmişte hemşirelerin görevleri sadece hastane ortamı ile sinırlı iken günümüzde toplumsal alanlarda da hizmet sürdüren ve toplum üzerinde etkisi, sorumluluğu olan bir meslek haline gelmiştir. $\mathrm{Bu}$ durumla birlikte günümüzde hemşirelik mesleği sadece hasta ve hastalığa odaklı olmaktan çıkmış, bütüncül bir sağlık anlayışıyla hareket eden bir meslek haline gelmiştir. Günümüzde modern hemşirelik rolleri;

- Bakım verme

- Danışmanlık

- Araştırma yapma

- Yönetim
- Karar verme/ Sorumluluk üstlenme

- Etkin iletişim

- Rehabilitasyonu sağlama

- Tedavi etme

- Profesyonelleşme / Bilgi ve becerilerini geliştirme olarak karşımıza çıkmaktadır. ${ }^{16}$

\section{Popüler kültürün toplum üzerine etkisi}

Toplum kavramı, belli bir bölgede yayılmış, ortak kültürü benimseyen insanların oluşturduğu, süreklilik kazanmış ilişkiler topluluğu olarak tanımlanmaktadır. ${ }^{17}$

Toplumlar benimsedikleri kültürle özelliklerini belirlerler. $\mathrm{Bu}$ özellikler toplumun kültürel, ekonomik, coğrafi, dini inanç ve değerleridir. Popüler kültür her topluma göre farklı şekillenir ve gelişen teknoloji, kitle iletişim araçları ve endüstri ile topluma yayılım gösterir. Türkiye' de gelişen teknoloji ve batı kültürünü benimseme hareketleri ile birlikte toplumsal olarak değişimler yaşanmaya başlanmıştır. $\mathrm{Bu}$ değişimler toplumdaki insanların kullandıkları eşyalarla birlikte bireylerin davranış şekilleri ve kıyafetlerinde de değişimleri beraberinde getirmiştir. ${ }^{18}$ Türk toplumundaki popüler kültür kişilerin ünlü insanlara ve yaşamlarına özenti duymasına neden olmuştur. Popüler kültürün baskın olmasında üzücü durumlardan ve gerçeklikten uzaklaşmak isteği etkili olmuştur. ${ }^{11}$ Popüler kültürün bu kadar yaygınlaşmasını ve etkin olmasını sağlayan en önemli etmenler kitle iletişim araçları ve buna bağlı olarak gelişen medya olmuştur.

Kitle iletişim araçları hem popüler kültürün yaygınlaşmasını sağlarken hem de popüler kültür sayesinde kendini şekillendirir ve biçimlendirir. Kitle iletişim araçlarının yararlı yönlerinin yanında bireyleri tüketime yönlendirme gibi olumsuz yönleri de bulunmaktadır. ${ }^{19-20}$ Genellikle egemen olan görüşler kitle iletişim araçlarının çok etkin olduğu yönündedir. Kitle iletişim araçları yalnızca toplum üzerinde davranış ve inancı değiştirme ya da güçlü tutmanın yanında toplumun gündem konusunu bulma ve oluşturmada kısacası toplumun neyi düşüneceğini belirlemede de etkin rol oynar. Kitle iletişim araçlarından en etkilisi ve en yaygın olanı televizyon, çeşitli yapımlarla 
(müzik, reklam, diziler, talk-show, yarışma vb.) toplumu eğlendirmeyi ve boşa zaman geçirmeyi amaçlamıştır. Televizyon popülerliği kullanarak ve güzel görseller sunarak bireyleri etkilemek, bazı mitleri güçlendirmek, düşünmeden uzaklaştırmak, eğlenceye yönlendirmek ve herkesin anlayabileceği şekilde evrensellik sağlamaktadır. Popüler kültür ve tüm bu etkenler birleştiğinde toplumda sanal gerçeklik kavramını oluşturur. ${ }^{21-22}$ Kitle iletişim araçları ve medyada yayılan popüler kültürde toplumun ataerkil yapısı öne çıkmakta ve kadının toplumsal sorumlulukları, kimlik ve statüleri bu doğrultuda șekillenmektedir. Bundan dolayı popüler kültür içerisinde toplumsal cinsiyet eşitsizlikleri, kadın bedeninin nesneleştirilmesi, kadınların insan yerine konulmaması ve aşağılanma gibi kötü olumsuzluklarla karşılaşılmaktadır. $\mathrm{Bu}$ olumsuzluklar toplumda kadınları etkileyen ekonomik ve siyasal problemleri oluşturmaktadır. Kadınlar iş hayatlarında, kurumsal alanlarda ya da toplumda bask1, ayrımcılık ve küçümsenme gibi durumlarla karşı karşıya kalmaktadır. ${ }^{23}$

\section{Popüler kültür bağlamında hemşirelik}

Popüler kültür, kitle iletişim araçları yoluyla oluşturduğu kültürü aktarırken toplumun değerlerini ve mesleki değerleri kullanabilmektedir. $\mathrm{Bu}$ meslekler arasında hemşirelik mesleği de bulunmaktadır. Hemşirelik mesleğini gerçek mesleki özelliklerinin, etik ve ahlaki ilkelerinin dışında gerçek dışı ve fantezi ortamında göstermektedir. Hemşirelik mesleğinin kutsal olarak gördüğü sağllğ koruma ve sürdürme, bakım verme ve iyileştirme gibi değerler popüler kültürde yer almamaktadır. Popüler kültürde hemşirelik mesleği ve hemşireler olumsuz imajlarla işlenir ve topluma bu şekilde yansitılır. Böylelikle hemşireliğin gerçek mesleki anlamını ve değerlerini kaybetmesine yol açar. Ayrıca popüler kültürün hemșirelik üzerindeki bu olumsuz imaj çalışması toplumdaki mesleki algının bozulmasina neden olurken, meslekte çalışanlara karşı bir önyargı oluşturur. Kitle iletişim araçları ve medya hemşirelik mesleğinin popüler kültürde sunulmasını sağlarken hem mesleki olarak saygınlığın hem de hemşirelik imajının bozulmasına neden olabilmektedir. ${ }^{24-25}$ Hemşirelik imaj1 uzun yıllar boyunca toplum tarafindan kalıplaşmış ve toplumda kadınlık ve güçsüzlük gibi imgelerle ilişkilendirilmiştir. $\mathrm{Bu}$ kalıplar hemşirelerin çalışmalarını ve benlik saygısını etkilemiştir. ${ }^{26}$ Modern toplumun hemşirelik algısını 4 ana faktör etkilemiştir. Bunlar;

- Hemşirelik mesleğinin sorunlu ve cinsel yönde gösterildiği medya

- Hemşirelik mesleğini aşağılayıcı eğlence yapımları

- Sayg1 duyulmayan bir meslek olarak gösterilen hemşirelikle ilgili çeşitli yapımlar

- Hemşirelik rollerini anlatamayan içerikler olarak sıralanabilir. ${ }^{27-28}$

Hemşirelik imajını etkileyen en önemli etmenlerden biri, popüler kültürde mesleği tasvir eden kitle iletişim araçlarıdır. Medyadaki görüntüler ve yazılanlar toplumun hemşirelik imajı üzerinde etkilidir. Hemşirelik mesleğinin medya imajı başarılı olarak kullanıldığında çok olumlu etkileri bulunmasına rağmen halen popüler kültür ve medyada hemşirelik yanlış ve olumsuz tasvir edilmektedir. $\mathrm{Bu}$ yanlış ve olumsuz görüntüler hemşirelik mesleğini seçen bireylerin sayısını ve niteliğini de büyük ölçüde etkileyebilirken, toplum içinde hemşirelik mesleğinin istenmeyen bir meslek olarak görülmesini de sağlayabilmektedir. ${ }^{29-30}$ Medyada öne çıkan bazı programlar hemşireleri hiçbir iş yapmayan çalışanlar olarak ve cinsel obje olarak göstererek hemşirelik imajının ve buna bağlı sorunların güçlenmesini sağlamaktadır. ${ }^{31}$ Özellikle popüler kültürün yayılmasında önemli bir kaynak olan televizyonda hemşireler dizi, reklam, film gibi yerlerde gerçek dışı tasvir edilmektedir. Buradaki tasvirlerde hemşireler; bir iyilik meleği olan hemşirelerden, cinselleştirilmiş hemşire tiplerine ve sağlik ekibi içinde diğerlerine göre daha az saygı duyulan çalışanlar gibi imgelerle nitelendirilmişlerdir. ${ }^{32}$ Sadece kadın hemşireler değil son zamanlarda hemşirelik mesleğindeki erkek hemşirelerinde artmasıyla televizyondaki erkek hemşirelerin imajları erkek olma, cinsellik, aşağılama gibi 
imgelerle yansıtılmış ve bu durum erkeklerin hemşirelik mesleğini seçmelerini olumsuz yönde etkilemiştir. ${ }^{33}$ Özellikle medyaya daha yakın olan gençlerde hastane konulu dizi ve filmlerdeki hemşirelik imajının olumsuz etkisi gözlemlenmektedir. ${ }^{34}$

Teknolojinin gelişmesiyle birlikte günümüzde internetin daha yaygın kullanılmaya başlanmasıyla birlikte internet ortamında da hemşirelerin imajı ile ilgili çeşitli tasvirler yapılmakta ve popüler kültürde etkisini arttırmaktadır. Aynı zamanda televizyonlarla karşılaştırıldığında daha yaygın ve kalıcı olduğu gözlenirken, televizyonda kaldırılan görüntülere internette daha kolay ulaş1labilmektedir. Hemşirelik imajının olumsuz görüntüleri internet ortamında eğlence ve reklam amacı ile kullanılmakta ve bu durum doğal gösterilmektedir. ${ }^{35}$ Her ne kadar görsel medyada hemşirelik imajına dair olumsuz tasvirler daha yaygin olsa da bu durum yazılı medyada da karşımıza çıkmakta, özellikle gazetelerde bu durum görülmektedir. Yapılan bir çalışmada gazetelerdeki haberlerde hemşire ve üniforması üzerinden cinsellik durumu oluşturan afişler ve reklamlara rastlanmıştır. $^{36}$ Bunlarla birlikte popüler kültürde hemşirelik mesleğini olumsuz şekilde tasvir eden birçok örnek bulunmaktadır. ${ }^{37}$

\section{Sonuç}

Son yıllarda gelişen teknoloji ile birlikte popüler kültür etkisini arttırmış ve evrensel olarak yayılmaya başlamıştır. Popüler kültür toplumsal yapının ve değerlerinin değişmesine neden olmaktadır. $\mathrm{Bu}$ değişimlerden etkilenen meslek gruplarından biri olan hemşirelik popüler kültürün etkisiyle toplumda olumsuz ve gerçek dışı imgelerle tasvir edilmekte ve toplumun hemşirelere yönelik algısını değiştirmektedir. Hemşireler toplumun algısından dolayı iş yaşamlarında farklı sorunlar yaşamakta ve bu algı bireylerin hemşirelik mesleğini seçmelerini de etkilemektedir. Oysa hayat kurtarıcı, iyileștirici, sağlığ koruyucu gibi toplumda çok önemli işlevleri olan hemşireler popüler kültürdeki tasvirleri nedeniyle toplum tarafından gerekli değer ve saygıyı görememektedir. Öte yandan hemşirelik imajının olumlu yönde değişiminin sağlanması için de çeşitli çalışmalar yapılmaktadır. Örneğin; Dünya Sağlık Örgütü hemşirelik tarihinde ve dünya da önemli yere sahip olan Florence Nightingale'in 200. doğum günü olan 2020 yılını 'Hemşire ve Ebeler Y1lı" olarak ilan etmiş ve tüm dünyada hemşirelere verilen değeri yükseltmeyi amaçlamıştır. 2019'un son aylarında başlayan, tüm dünyayı ve ülkemizi etkisi altına alan Koronavirüs (Covid-19) salgınına karşı en önde savaşanlardan biri olan hemşireler, sağlık alanındaki etkisini, fedakarlığını ve kahramanlığını bir kez daha gözler önüne sermiştir. ${ }^{38}$ Kutsal bir meslek olan hemşireliğin popüler kültürdeki olumsuz tasvirleri düzeltilmeli, bu konuda mesleki örgütler bir araya gelerek önlem alınmasını sağlamalı ve kitle iletişim araçlarında olumsuz hemşirelik tasvirlerinin yayınlanmasına izin verilmemelidir.

\section{Yazar Katkıları}

Fikir, tasarım, literatür taraması, analiz, makale yazımı, denetleme, onay: EÖÇ, ZC, FK, HHÇ.

\section{Çıkar Çatışması Beyanı}

Yazarların herhangi bir çıkara dayalı ilişkileri yoktur.

\section{Araştırma Desteği}

Çalışmayı maddi olarak destekleyen kurum/kişiler bulunmamaktadır.

\section{Beyanlar}

Çalışmanın daha önce sunulduğu konferans/dergi yoktur.

\section{Hakem Değerlendirmesi}

D1ş bağımsız.

\section{Kaynaklar}

1. Büyükyonca G. Türk Televizyon Dizilerinin Geleneksel Türk Aile Yapısına Olan Etkisinin Popüler Kültür Bağlamında İncelenmesi: Bir Aile Dizisi Üzerine Analiz (YL Tezi). İstanbul: Marmara Üniversitesi Sosyal Bilimler Enstitüsü; 2019.

2. Eskicioğlu F. Popüler Kültür Ögelerinin Sosyal Medyada Yansıması: Gündem Belirleme Kuramı Çerçevesinde İçerik Analizi (YL Tezi). İzmir: Yaşar Üniversitesi Sosyal Bilimler Enstitüsü; 2017.

3. Tezer D. Televizyon -Kültür İlişkisi Bağlamında Popüler Kültürün Algılanış Biçimleri Kahramanmaraş Örneği (YL Tezi). Konya: Selçuk Üniversitesi Sosyal Bilimler Enstitüsü; 2013. 
4. Çelik AS, Pasinlioğlu T, Kocabeyli T, Çetin S. Hemşirelik mesleğinin toplumdaki imajının belirlenmesi. Florence Nightingale Hemşirelik Dergisi, 2013; 21.3:147-153.

5. Nazik E, Arslan S. Hemșirelik mesleğinin geleceği: Öğrencilerin beklentileri. Bozok Tip Dergisi, 2014; 4.1: 33-40.

6. Darbyshire, P. Heroines, hookers and harridans: Exploring popular images and representations of nurses and nursing. Contexts of Nursing; 2010:51-64.

7. Simșek S. Yaşam Tarzı Üzerinde Popüler Kültürün Belirleyiciliği ve Kitle İletişim Araçlarının Etkisi: Türkiye'de Punk Kültürü Örneği (YL Tezi). Konya: Selçuk Üniversitesi Sosyal Bilimleri Enstitüsü; 2010.

8. Türk Dil Kurumu (TDK). Güncel Türkçe Sözlük. http://tdk.gov.tr/. Erişim Tarih: 15.05.2020.

9. Yorulmaz M. Popüler Kültür Bağlamında Beden Alg1sı (YL Tezi). Canakkale: Çanakkale On Sekiz Mart Üniversitesi Sosyal Bilimler Enstitüsü; 2015.

10. Atça ÇH. Popüler Kültür ile Tüketim Kültürü İlişkisi Üzerine Bir Araștırma (YL Tezi). İstanbul: Marmara Üniversitesi Sosyal Bilimler Enstitüsü; 2019.

11. Asiltürk F. Popüler Kültür Tüketimi ve Basılı Popüler Kültür Tüketim Nesnelerinin Sanat Nesnesi Olarak Kullanımı (YL Tezi). Isparta: Süleyman Demirel Üniversitesi Güzel Sanatlar Enstitüsü; 2019.

12. Eşer İ, Orkun N, Çetin P. hemşirelik imajı ve 1950'li yıllarda bir seri ilan. Dokuz Eylül Üniversitesi Hemsirelik Fakültesi Elektronik Dergisi, 2017; 10.4.

13. Uluslararası Hemşireler Konseyi (The International Council of Nurses- ICN). Definition of Nursing. https://www.icn.ch/nursing-policy/nursing-definitions. Erişim Tarihi: 16.05.2020

14. Amerikan Hemşireler Derneği (American Nurses AssociationANA). What is nursing? https://www.nursingworld.org/practice-policy/workforce/whatis-nursing/. Erişim Tarihi: 16.05.2020

15. Türk Hemşireler Derneği. Hemșirelik Yönetmeliği. https://www.thder.org.tr/hemsirelik-yonetmeligi. Erişim Tarihi: 16.05.2020.

16. Gedük AE. Hemşirelik mesleğinin gelişen rolleri. Să̆lık Bilimleri ve Meslekleri Dergisi, 2018; 5.2: 253-258.

17. Güneş UPE. Toplumsal değişim, teknoloji ve eğitim ilişkisinde sosyal ağların yeri. Açıkögretim Uygulamaları ve Araştırmaları Dergisi, 2016; 2.2: 191-206.

18. Coşgun M. Popüler kültür ve tüketim toplumu.Batman Üniversitesi Yaşam Bilimleri Dergisi, 2012, 1.1: 837-850.

19. Şahin MC. Türkiye de gençliğin toplumsal kimliği ve popüler tüketim kültürü. Gazi Üniversitesi Gazi Eğitim Fakültesi Dergisi, 2005; 25.2: 157-181.

20. Karakoç E. Medya Aracılığıyla Popüler Kültürün Aktarılmasında Toplumsal Değişkenlerin Rolü (YL Tezi). Konya: Selçuk Üniversitesi Sosyal Bilimler Enstitüsü; 2007.

21. Güllüoğlu Ö. Bir Kitle iletişim aracı olarak televizyonun popüler kültür ürünlerini benimsetme ve yayma işlevi üzerine bir değerlendirme. Global Media Journal: Turkish Edition, 2012; 2.4

22. Zorlu Y. Türkiye'de bir popüler kültür aracı olarak televizyon. Erciyes İletișim Dergisi, 2016; 4.3.

23. Baydar V. Popüler kültürde mizojini. Electronic Turkish Studies, 2013; 8.12

24. Akkaya R, Darıcı S. Dizi ve filmlerde hemşire imajının kültür endüstrisi ve popüler kültür bağlamında incelenmesi: Türkiye'den iki vakanın analizi. International Journal of Multidisciplinary Studies and Innovative Technologies, 2019; 3.2: 219-224.

25. Fealy GM. 'The good nurse': Visions and values in images of the nurse. Journalof Advanced Nursing, 2004; 46.6: 649-656.

26. Takase M, Kershaw E, Burt L. Does public image of nurses matter? Journal of Professional Nursing, 2002; 18.4: 196-205.

27. Girvin J, Jackson D, Hutchınson M. Contemporary public perceptions of nursing: a systematic review and narrative synthesis of the international research evidence. Journal of Nursing Management, 2016; 24.8: 994-1006.

28. Ferns T, Chojnacka I. Angels and swingers, matrons and sinners: Nursing stereotypes. British Journal of Nursing, 2005; 14.19: 1028-1032.

29. Kalisch BJ, Begeny S, Neumann S. The image of the nurse on the internet. Nursing Outlook, 2007; 55.4: 182-188
30. Weaver R,Salamonson Y, Koch J, Jackson D. Nursing on television: Student perceptions of television's role in public image, recruitment and education. Journal of Advanced Nursing, 2013; 69.12: 2635-2643.

31. Summers S, Summers H. Savinglives: Why the media'sportayal of nurses puts us all at risk. New York: Kaplan, 2009.

32. Guo JW, Tay DL, Litchman ML. Hashtags and heroes: perceptions of nursing on twitter following a high profile nurse arrest. Journal Of Professional Nursing, 2019; 35.5: 398-404.

33. Weaver R,Ferguson C, Wilbourn M. Men in nursing on television: Exposing and reinforcing stereotypes. Journal of Advanced Nursing, 2014; 70.4: 833-842.

34. Glerean N,Hupli M, Talman K, Haavisto E. Young peoples' perceptions of the nursing profession: An integrative review. Nurse Education Today, 2017; 57: 95-102.

35. Kelly J, Fealy GM, Watson R. The image of you: Constructing nursing identities in youtube. Journal of Advanced Nursing, 2012; 68.8: 1804-1813.

36. Eyikara E, Eyüboğlu G, Baykara GZ. Hemşirelik mesleğinin gazetelere yansıması: On beş yıllık değişim. Anadolu Hemşirelik ve Sağllk Bilimleri Dergisi, 2019; 22.1: 41-48.

37. Mcallister M, Brıen DL, Piatti-Farnell L. Tainted love: Gothic imaging of nurses in popular culture. Journal Of Advanced Nursing, 2018; 74.2: 310-317.

38. Karasu F, Çopur ÖE. Koronavirus (COVID-19) Vakaları Artarken Salgının Ön Safindaki Bir Yoğun Bakım Hemşiresi:“Cephede Duran Kahramanlar”. Yoğun Bakım Hemşireliği Dergisi, 2020; 24.1: 11-14. 